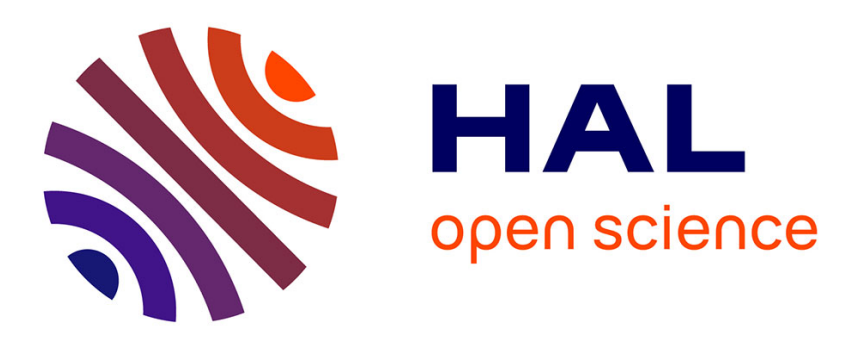

\title{
Health conditions and the risk of home injury in French adults: results from a prospective study of the MAVIE cohort
}

Madelyn Yiseth Rojas Castro, Marta Avalos, Benjamin Contrand, Marion Dupuy, Catherine Sztal-Kutas, Ludivine Orriols, Emmanuel Lagarde

\section{To cite this version:}

Madelyn Yiseth Rojas Castro, Marta Avalos, Benjamin Contrand, Marion Dupuy, Catherine SztalKutas, et al.. Health conditions and the risk of home injury in French adults: results from a prospective study of the MAVIE cohort. Injury Prevention, 2022, 28 (2), pp.6. 10.1136/injuryprev-2020-044033 . hal-03481699

\section{HAL Id: hal-03481699 \\ https://hal.inria.fr/hal-03481699}

Submitted on 16 Dec 2021

HAL is a multi-disciplinary open access archive for the deposit and dissemination of scientific research documents, whether they are published or not. The documents may come from teaching and research institutions in France or abroad, or from public or private research centers.
L'archive ouverte pluridisciplinaire HAL, est destinée au dépôt et à la diffusion de documents scientifiques de niveau recherche, publiés ou non, émanant des établissements d'enseignement et de recherche français ou étrangers, des laboratoires publics ou privés. 


\title{
Health conditions and the risk of home injury in French adults: results from a prospective study of the MAVIE cohort
}

\author{
Madelyn Yiseth Rojas Castro, ${ }^{1,2}$ Marta Avalos, ${ }^{1,3}$ Benjamin Contrand, ${ }^{1,2}$ \\ Marion Dupuy, ${ }^{4}$ Catherine Sztal-Kutas, ${ }^{4}$ Ludivine Orriols, ${ }^{1,2}$ Emmanuel Lagarde (i) 1,2
}

\begin{abstract}
Additional supplemental material is published online only. To view, please visit the journal online (http://dx.doi. org/10.1136/injuryprev-2020044033)
\end{abstract}

'U1219, INSERM, Bordeaux, Nouvelle-Aquitaine, France ${ }^{2}$ U1219, Universite de Bordeaux, Bordeaux, Aquitaine, France

${ }^{3}$ SISTM Team, Inria, Talence, Aquitaine, France

${ }^{4}$ Calyxis, Centre of Risk Expertise, Niort, France

Correspondence to Emmanuel Lagarde, Bordeaux Aquitaine, France; emmanuel. lagarde@u-bordeaux.fr

Received 10 October 2020 Accepted 10 August 2021

Check for updates

(C) Author(s) (or their employer(s)) 2021. No commercial re-use. See rights and permissions. Published by BMJ.

To cite: Rojas Castro MY Avalos M, Contrand B, et al. Inj Prev Epub ahead of print: [please include Day Month Year]. doi:10.1136/

injuryprev-2020-044033

\begin{abstract}
Background Home injury (HI) is a significant cause of mortality and morbidity in adults of all ages. Health conditions significantly impact $\mathrm{HI}$ among old adults, but little is known for other adults.

Study design Prospective cohort study.

Objective We assessed the associations between health-related factors and HI's risk in a French study, the MAVIE (Mutualistes pour la recherche contre les Accidents de la VIE courante) cohort.

Methods Poisson mixed models were fitted using health-related data information (diseases, treatments and disabilities) at baseline and the number of injuries prospectively recorded during the follow-up, adjusting for significant sociodemographics and exposure to a range of home activities. Attributable fractions were estimated based on risk ratio (RR) estimations measured in the fully adjusted models.
\end{abstract}

Results A total of 6146 dwelling adults aged 15 or older were followed up for 5.1 years on average. Vertigo or dizziness ( $R R=2.36,95 \% \mathrm{Cl} 1.06$ to 5.01$)$ and sciatica or back pain ( $R R=1.49,95 \% \mathrm{Cl} 1.08$ to 2.05) were independently associated with an increased risk of $\mathrm{HI}$. These two groups of conditions showed the most significant associations among people aged 15-49, whereas musculoskeletal diseases other than rachialgias and arthropathies were the most significant healthrelated risk factor in people aged 50 and older. Sciatica or back pain represented the highest burden of HIs in overall adults (8\%) and among people aged 15-49 (12\%).

Conclusion Our results suggest that adults with musculoskeletal disorders and vertigo or dizziness symptoms have a higher risk of $\mathrm{HI}$, regardless of age.

\section{INTRODUCTION}

Home injuries (HIs) represent approximately onethird of the global burden of injuries. ${ }^{1}$ In the EU-28, HIs caused an annual average of 85000 fatalities, 1.5 million hospital admissions and 9 million emergencies between 2012 and 2014 . $^{2}$ Home has been identified as the most prevalent location for injuries resulting in hospitalisation and is second to roads as the location for fatal injuries. ${ }^{3}$ HIs affect people of all ages. However, among adults, HIs are more frequent in people aged 65 years or over. Falls are the principal mechanism of fatal and non-fatal HIs. ${ }^{2}$

Multiple studies have identified health-related factors associated with falls in the elderly, including lack of strength gait and balance; mobility impairment ${ }^{4-6}$; back pain $^{7}{ }^{8}$; $\operatorname{arthropathies~}^{6}{ }^{9}$; dizziness and vertigo ${ }^{610} 11$; obesity ${ }^{12}$; diabetes ${ }^{569}$; cardiovascular conditions ${ }^{569}$; chronic obstructive pulmonary disease ${ }^{9}$; urinary incontinence ${ }^{6}$; visual and hearing impairments ${ }^{5}$; cognition impairments caused by neurological conditions such as Parkinson's disease, Alzheimer's disease or other types of dementia ${ }^{4-6}$; and sleeping problems; anxiety; or depression. ${ }^{4-69}$ Frailty status, ${ }^{13}$ the presence of two or more concurrent conditions ${ }^{6}$ and certain medications, such as psychotropics, antidepressants, anxiolytics, sedatives or hypnotics, ${ }^{14}$ opioids,${ }^{15}$ cardiac medication, diuretics, antidiabetic medication ${ }^{5}$ and polypharmacy, ${ }^{16}$ are also associated with falls in the elderly.

Among young and middle-aged adults, understanding the impact of health risk factors on $\mathrm{HI}$ is poor. ${ }^{17}{ }^{18}$ Regarding the risk of occupational injuries, there is some evidence of the role of hearing impairments, neurotic illness, diabetes, ${ }^{18}$ epilepsy and sedating medication. ${ }^{19}$ Regarding falls in the bathroom, drugs and alcohol, cardiovascular disease, neuromuscular disorders and diabetes were identified as risk factors at all ages, especially 41-60 years old. ${ }^{20}$ Conditions such as back pain, sleeping problems, anxiety, depression, cardiovascular diseases and diabetes can also be frequent in young and middle-aged adults, which justifies evaluating their impact on adults of all ages.

One of the objectives of the prospective MAVIE (Mutualistes pour la recherche contre les Accidents de la VIE courante) cohort study ${ }^{21}$ is to identify new specific, modifiable risk factors to design interventions allowing to reduce predisposition and potential susceptibility to Home, Leisure and Sports Injuries (HLIs). The purpose of this study was to assess associations of health-related factors on the risk of non-fatal $\mathrm{HI}$ in adults of all ages.

We hypothesise that focusing on specific healthrelated factors to design prevention interventions, which have shown to be effective in reducing falls in the elderly, may also mitigate HIs in middle-aged and young adults.

\section{METHODS}

\section{Study design and recruitment}

The MAVIE cohort is a web-based prospective cohort study conducted in France, with a longitudinal follow-up of HLIs. ${ }^{21}$ All households in France and French overseas territories were eligible to participate. The recruitment process began in 
November 2014. This study analysed the data collected up to 31 December 2019.

Cohort management was entirely online, including invitations, registration and data collection. Participants were recruited through an email invitation sent to their insurees by three mutual insurance companies, press releases, social media, posters and flyers.

We asked potential participants to choose a household reference member in charge of completing a web-based questionnaire for the household. Consenting members of each household were asked to provide individual information. In an attempt to address the foreseeable under-representation of the elderly who may have difficulties using computers, caregivers were invited to represent and participate on behalf of one older person. We described other attempts to reduce bias in the MAVIE observatory in elsewhere. ${ }^{21}$

\section{Follow-up}

Every 3 months, household reference members received an email reminder to report any injury event to any consenting household members during the follow-up. If no injury had occurred, a link in the email allows reporting with a single click. An invitation to report events was also included in the monthly cohort newsletter. Still, events could be reported at any time.

\section{Participant data and selection}

The inclusion criteria for participation in the MAVIE cohort were as follows: (1) residing in France; (2) being able to answer the questionnaires in French; (3) having access to and being able to use the internet (at least the reference member). The baseline sample was defined as the participants aged 15 or over who answered at least one question of the individual inclusion questionnaire. We excluded those who lived in hospitals and retirement or long-term care institutions. We only considered participants whose follow-up could be confirmed (by injury or non-injury report, questionnaire update, death or study leave request). We also excluded those participants who did not answer the daily schedule questions, necessary for the calculation of time-at-risk.

\section{Home injuries}

This study focused on unintentional HIs or its premises. We excluded all events involving illnesses or medical symptoms. We excluded events that occurred before or on the same date as the date of consent and those for which information about the type of medical care or the circumstances of occurrence was not reported. Finally, we excluded injuries that occurred during sleeping time, considered unlikely.

Data included activity and location, mechanisms and type of medical care of the injury event. We defined HIs as severe when emergency care or hospital inpatient care was required.

\section{Individual characteristics}

\section{Relative time distribution}

Participants were asked to report their typical daily schedule on a weekday and on a weekend, the time spent at home and in different domestic settings (dining room, bedroom, garden, etc). The average duration was also reported for domestic work, gardening and do-it-yourself (DIY) activities. Time spent on each activity was categorised as frequent (over the 75 th percentile), occasional or null.
Socioeconomic, demographic characteristics and alcohol consumption

Gender, age, occupational status, education level, living situation, household incomes and alcohol consumption were studied at baseline. Occupational status groups were unemployed, homemakers, and retirees and students and employees. Responses to education status were assigned to educational attainment levels by age groups. We considered a low level of education high school or vocational studies, or lower for participants aged 20-54, and primary studies or lower for other ages. Annual household incomes were assigned to classes according to the French population's percentiles reported in 2015 (low: $\leq 30$ th percentile, middle: 30 th-80th percentile, high: $\geq 80$ th percentile). The categories of the frequency of alcohol consumption were less than two times a week, and two or more times a week.

\section{Health conditions and medications}

At inclusion, participants were invited to report their history of diseases and treatments over the previous 12 months.

Medical conditions were grouped into the following clinically homogeneous categories: cardiovascular diseases, respiratory diseases, digestive diseases, genitourinary diseases, endocrine diseases, sciatica or back pain, arthropathies, other conditions of the musculoskeletal system, eye diseases, depression, anxiety, sleeping disorders (including treatment with antidepressants, anxiolytics or hypnotics), migraine or headache, vertigo or dizziness, chronic mental diseases (Parkinson's disease, Alzheimer's disease or other senile dementia, epilepsy and antiepileptic medicines) and cancer. Participants were also asked to report whether they were suffering from impairments or disabilities related to vision, hearing, mental, intellectual, or psychological, and mobility.

We defined polypharmacy as a reported number of medications of four or more, ${ }^{16}$ and comorbidity as the report of two or more diseases ${ }^{22}$ at any time in the previous 12 months. The history of injuries (excluding sports injuries) over the past 12 months was also reported.

\section{Statistical analyses}

Data were analysed using R V.3.6.1 (The R Foundation for Statistical Computing, Vienna, Austria).

We defined the follow-up period (FP) from the consent date to the date of the last information reported: injury or non-injury report, the questionnaires update date, the cohort exit date, the death date. We calculated the proportion of time spent awake at home (PTAH) as the proportion of hours on a weekday or weekend when the person was neither away from home nor sleeping. We considered the time-at-risk as:

Time-at-risk $=\left(\mathrm{PTAH}_{w} \times\right.$ No. FPw $)+\left(\mathrm{PTAH}_{w n} \times\right.$ No. FPwn $)$,

where $P$ TAH was the time spent awake at home regular weekday, $P T A H_{w n}$ on a regular weekend, No. FP ${ }_{w}$ the number of weekdays in the follow-up period and No. FP ${ }_{w n}$ the number of weekends. We calculated the proportion of time-at-risk as:

$\%$ Time-at-risk $=($ Time-at-risk/Follow-up duration $) \times 100 \%$. (2)

\section{Risk factor analysis}

Poisson mixed models were used to fit the number of HIs during the estimated exposure distribution in the person-time at risk for injury. Random effects were included to consider the cluster structure of data in households. All models were fitted using the Template Model Builder R package. ${ }^{23}$ Risk ratios (RR) were 


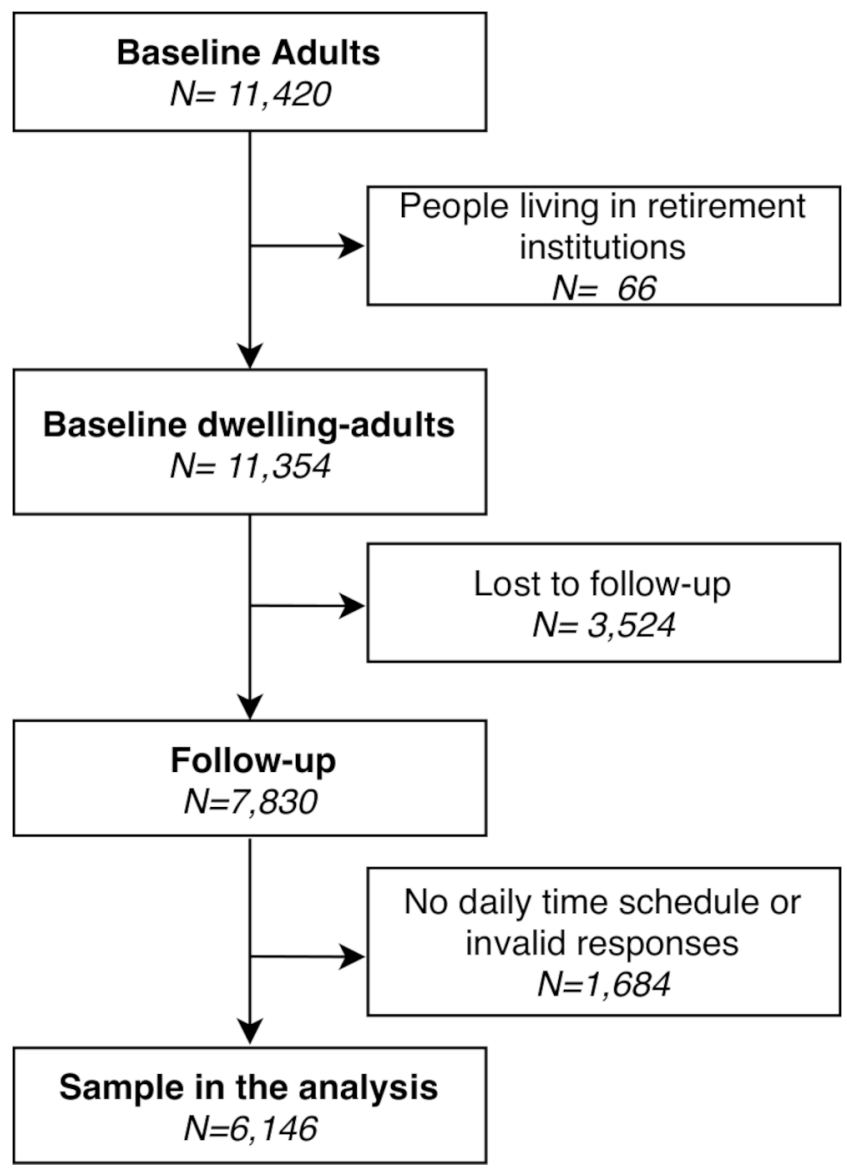

Figure 1 Flowchart of study participants.

calculated conditionally on the random effects, and the $95 \%$ CIs were calculated using the profile method. ${ }^{24}$ We adopted a complete case approach.

We fitted individual crude regression models to each health condition. Then, we conducted a two-step variable selection procedure. First, we adjusted each model by age, gender and history of injuries in all models, and we selected the most important associations $\left(p_{\text {adj }}<0.10\right)$. Second, we fitted the models to each health-related factor, adjusting for significant adjustment variables selected in the previous step. Finally, we selected the most important associations for the fully adjusted model (excluding comorbidity). Benjamini-Hochberg corrected $\mathrm{p}$ values were computed. ${ }^{25}$ The same methodology was used to construct models stratified by two distinct age groups (15-49 years old and 50 years or older).

The attributable fraction (AF) was estimated using the adjusted RR of the fully adjusted models, as suggested by Flegal and colleagues. ${ }^{26}$

\section{RESULTS}

Between November 2014 and December 2019, 11420 adults registered in the MAVIE cohort and responded to baseline questionnaires. Among them, 9429 were household reference members representing themselves and/or another household member. Sixty-six participants reported that living in a retirement institution, and 3524 participants did not provide follow-up data. Another 1684 participants did not provide their daily schedule (figure 1). The sample size was 6146 participants from 5122 households.
The median follow-up was 4.0 years $(\mathrm{Q} 1=3.6, \mathrm{Q} 3=4.5)$. The overall follow-up duration was 4800 persons-time. The loss to follow-up was $13 \%$.

Among the 6146 individuals of the study, 244 left the cohort during the follow-up. Nineteen of them were reported by the reference member to have died, 16 from illness and 3 of unknown causes. Thirty-one participants left the study due to changes in household composition. The remaining 191 participants did not report any reasons for leaving the study.

Socioeconomic, demographic characteristics and alcohol consumption levels were similar to those of the study sample and baseline sample (table 1). However, dropout was more frequent among young adults, students and employees, and among members of low-income households.

\section{Baseline characteristics}

Socioeconomic, demographic characteristics and alcohol consumption

Table 1 shows the socioeconomic, demographic characteristics and alcohol consumption of the sample at baseline. Sample characteristics differed from those of the overall French population. Participants aged $50-74$ were over-represented (62\% vs $35 \%$ in the French population, 2015). Students and employees were under-represented (49\% vs 57\%). People with low education attainment level were under-represented ( $8 \%$ vs $44 \%)$. Finally, only $12 \%$ of household reference members reported an annual income lower than the 30th percentile of French households.

The median proportion of time spent at home awake was $48 \%(\mathrm{Q} 1=36 \%, \mathrm{Q} 3=58 \%)$. Adults older than 50, unemployed, retirees, homemakers and those who reported gardening, DIY and domestic activities were those who spent the most time at home (online supplemental material 1).

\section{Health conditions, diseases and medications}

Among the 6146 participants, $67 \%$ reported at least one health condition (figure 2). They were older, with a median age of 60 compared with 35 for those who did not report any health condition. Figure 2 shows the most frequently reported health conditions by age group. Almost half of the participants (48\%) reported more than one health condition. The most frequently reported conditions among adults aged $15-49$ years were depression, anxiety or sleeping disorders, and among adults aged 50 and older, cardiovascular diseases. Eight per cent of participants reported at least one type of injury in the last 12 months.

\section{Home injuries}

During follow-up, $12 \%$ of the participants reported at least one HI, of which 946 occurred while awake. Most of HIs were minor injuries, and only $28 \%$ required either hospitalisation or emergency care. Falling was the main mechanism of HI (39\%), domestic and gardening activities (42\%), the most frequents activities and the garden (25\%) the most frequent location (online supplemental material 2).

\section{Health risk factor analysis}

Adjusting for the selected variables of block 1 (online supplemental material 3), vertigo or dizziness, sciatica or back pain, arthropathies, other musculoskeletal system diseases, depression, anxiety or sleeping disorders, and comorbidity were associated with an increased risk of $\mathrm{HI}$ in adults of all ages with a small or moderate effect (block 2, online supplemental material 3). In the fully adjusted model (table 2), vertigo or dizziness and sciatica or back pain remained associated with an increased risk of HI 
Table 1 Description of the demographic, socioeconomic and other characteristics at inclusion time of MAVIE (Mutualistes pour la recherche contre les Accidents de la VIE courante) dwelling adults: baseline and analysed sample

\begin{tabular}{|c|c|c|}
\hline & \multirow{2}{*}{$\begin{array}{l}\text { Baseline sample } \\
\mathrm{N}(\%)\end{array}$} & \multirow{2}{*}{$\begin{array}{l}\text { Analysed sample } \\
\mathrm{N}(\%)\end{array}$} \\
\hline & & \\
\hline All & 11354 & 6146 \\
\hline \multicolumn{3}{|l|}{ Gender } \\
\hline Male & $5326(47)$ & $2933(48)$ \\
\hline Female & $6028(53)$ & $3213(52)$ \\
\hline \multicolumn{3}{|l|}{ Age (years) } \\
\hline $15-29$ & $1074(9)$ & $490(8)$ \\
\hline $30-49$ & $3251(29)$ & $1611(26)$ \\
\hline $50-74$ & $6542(58)$ & $3823(62)$ \\
\hline $75+$ & $487(4)$ & $222(4)$ \\
\hline \multicolumn{3}{|l|}{ Employment status } \\
\hline Students, employees & $4810(52)$ & $2998(49)$ \\
\hline Unemployed, retirees and homemakers & $4395(48)$ & $3042(51)$ \\
\hline Missing & 2149 & 106 \\
\hline \multicolumn{3}{|l|}{ Level of educational attainment by age* } \\
\hline Low & $823(9)$ & $474(8)$ \\
\hline High & $8434(91)$ & $5658(92)$ \\
\hline Missing & 2097 & 14 \\
\hline \multicolumn{3}{|l|}{ Living alone } \\
\hline No & $9116(81)$ & $4893(80)$ \\
\hline Yes & $2135(19)$ & $1205(20)$ \\
\hline Missing & 103 & \\
\hline \multicolumn{3}{|l|}{ Frequency of alcohol consumption } \\
\hline Less of 2 times a week & $4850(60)$ & $3422(58)$ \\
\hline 2 times a week or more often & $3247(40)$ & $2496(42)$ \\
\hline Missing & 3257 & 228 \\
\hline \multicolumn{3}{|l|}{ DIY/gardening } \\
\hline Never & 3124 (39) & $2080(36)$ \\
\hline Occasional & $3339(42)$ & $2519(43)$ \\
\hline Frequent & $1573(20)$ & $1228(21)$ \\
\hline Missing & 3318 & 319 \\
\hline \multicolumn{3}{|l|}{ Domestic } \\
\hline Never & $1928(24)$ & $1284(22)$ \\
\hline Occasional & $4499(56)$ & $3306(57)$ \\
\hline Frequent & $1561(20)$ & $1201(21)$ \\
\hline Missing & 3366 & 321 \\
\hline Household income levelt & $n=9429$ & $n=5122$ \\
\hline Low & $1176(14)$ & $563(12)$ \\
\hline Middle & $3320(41)$ & $1850(40)$ \\
\hline High & $3655(45)$ & $2198(48)$ \\
\hline Missing & 1273 & 511 \\
\hline
\end{tabular}

* Level of educational attainment by age groups according to French population in 2015 (low: <50th percentile, high: $\geq 50$ th percentile).

tHousehold income according to percentiles of salaries of the French population in 2015 (low: $\leq 30$ th percentile, middle: 30 th-80th percentile, high: $\geq 80$ th percentile), frequencies calculated using the household as the unit.

DIY, do-it-yourself; $n$, number of households; $N$, number of responders.

and with AFs of $1.9 \%$ and $8.1 \%$, respectively. The contribution of depression, anxiety and sleeping disorders was also important $(\mathrm{AF}=5.5)$, but the association was weaker than the conditions named above ( $\mathrm{RR}=1.28,95 \% \mathrm{CI} 0.96$ to 1.70$)$.

Results of the fully adjusted models were similar for participants aged 15-49, but the effects of sciatica or back pain and vertigo or dizziness were higher than among adults of all ages (table 3). The category of other musculoskeletal system diseases covered the only conditions significantly associated with the risk of HI among participants aged 50 or older (table 3). All models converged, and their residuals were validated, discounting problems, such as over/underdispersion and zero inflation.

\section{DISCUSSION}

To our knowledge, we present here the first study to evaluate the association of health conditions with the risk of non-fatal HIs in adults of all ages. In contrast with previous studies, we have measured individual time spent at home and the estimated exposure distribution in the person-time at risk for injury. This is particularly relevant since people suffering from a health condition may spend more time at home.

We followed up 6146 cohort participants residing in French households, of whom 12\% suffered at least one HI over an average of 5.1 years. The same proportion was 14\% among those who reported at least one health condition. Among the 21 health conditions reported at inclusion, we identified sciatica or back pain problems and vertigo or dizziness as the main risk factors, with an estimated AF of $8.1 \%$ and $1.9 \%$, respectively.

This unprecedented finding of substantially increased risk of HI among adults under 50 years old with sciatica or back pain $(R R=2.26)$ and vertigo or dizziness $(R R=4.59)$ is striking not only because of these high association measures but also because of a substantial estimated $\mathrm{AF}$ (11.9\% and 3.2\%, respectively). For people over 50 years old, musculoskeletal diseases (other than rachialgia and arthropathies) are the only condition that remained significant in the fully adjusted model. These same factors associated with mobility emerged when we analysed only falls and unintentional struck, whereas this was not the case for other HIs. That suggests that most health conditions affecting the risk of $\mathrm{HI}$ are increasing the risk of falling. Other factors usually associated with injuries and falls, such as gender, age, vision and hearing impairments, polypharmacy and alcohol consumption, did not appear to be associated with an increased risk of $\mathrm{HI}$ in this study.

Musculoskeletal conditions (including back pain) and sciatica are well-known risk factors for occupational injury, likely due to overexertion. Overexertion was reported only in the $18 \%$ of injuries of people suffering from musculoskeletal conditions. Consistent with previous findings, the effects of arthropathies $(\mathrm{RR}=1.37)$ and other musculoskeletal conditions $(\mathrm{RR}=1.57)$ were more relevant among adults over 50 years old. ${ }^{69}$ In contrast with previous studies, back pain did not appear to be associated with an increased risk of $\mathrm{HI}$ in adults over $50 .{ }^{78}$ One possible explanation is that older people may favour chronic conditions over problems such as back pain when self-reporting. We hypothesise that poor posture might affect housework performance, increasing general injury susceptibility. Decreased cognitive function due to chronic pain ${ }^{27}$ or opioid use ${ }^{15}$ might also raise HI risk.

Vertigo or dizziness increased the risk of HI among young adults, but not among those aged 50 or older. This group of symptoms may be related to vestibular migraine, benign paroxysmal positional vertigo and Meniere's disease, ${ }^{28}$ rather than age-related conditions such as Parkinson's disease, or cerebellum and oculomotor brainstem syndrome. ${ }^{29}$ Other possible causes of vertigo, such as hypoglycaemic episodes or postural hypotension, have been partially controlled for by adjusting for other conditions such as endocrine diseases and cardiovascular diseases.

We found a slightly increased risk of $\mathrm{HI}$ among participants reporting depression, anxiety or sleeping disorders. Consistently, 


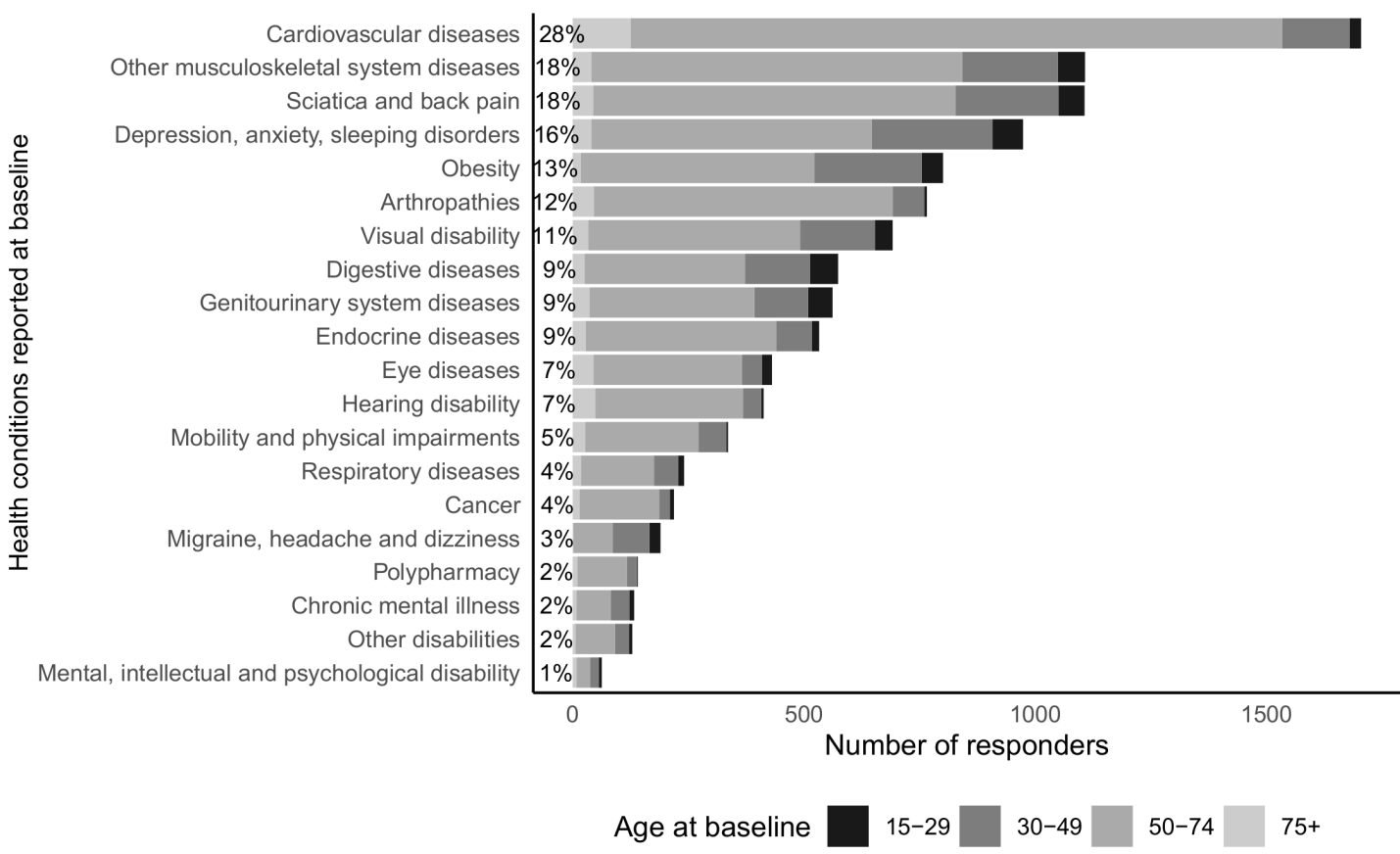

Figure 2 Self-reported health conditions at inclusion: Diseases reported during the 12 months prior to baseline, disabilities and obesity at the time of inclusion by the analysed dwelling adults of the MAVIE (Mutualistes pour la recherche contre les Accidents de la VIE courante) cohort, stratified by age groups (at inclusion). Sample size $\mathrm{N}=6146$.

Palmer and colleagues highlighted an increased risk of occupational injury among people with emotional conditions and a moderate effect among sedative consumers. ${ }^{18}$ Another explanation might be the difficulties in assessing risks and a reduced motivation to correct them in people who have affective psychological disorders.

Unlike other studies, ${ }^{30}$ we found no association regarding age and disability. Because we could account for the time spent at home, our results confirm that exposure time is the main explanation. ${ }^{31}$ A relevant self-perception of disability allows

Table 2 Factors associated with the incidence of $\mathrm{HI}$, relative to the time at risk at home, in adults of the MAVIE (Mutualistes pour la recherche contre les Accidents de la VIE courante) cohort (fully adjusted model)

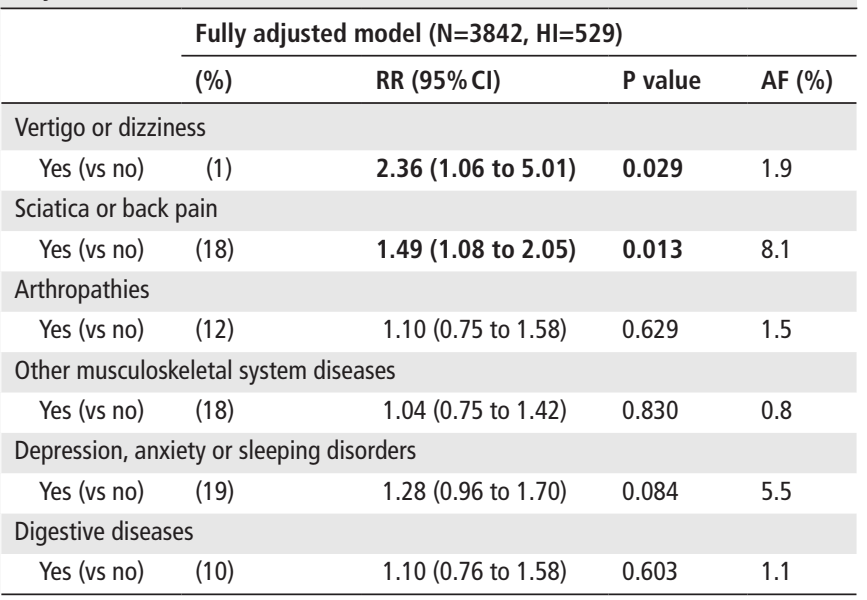

Poisson model was adjusted by the offset term time spent at home during the follow-up, random effect in the variable household, age, gender, history of previous injuries, household income level, living alone, and DIY and gardening.

Bold indicates $p$ values $<0.05$.

$A F$, attributable fraction; $\mathrm{HI}$, number of home injuries; $\mathrm{N}$, number of responders. compensation for an increased risk of injury, enabling enhanced care in daily activities and avoiding risky tasks and domestic hazards. People with moderate conditions, more active in domestic work and less aware of risks might be more exposed to hazards together they might insufficiently regulate their behaviour. On the other hand, these effects may be mitigated by the beneficial impacts of domestic activities, ${ }^{32}$ for example, by improving executive functions. ${ }^{33}$

Lessons for prevention from our results include better awareness of risks at home for people with diseases related to the musculoskeletal system. Our results also highlight the preventive role of physicians when dealing with vulnerable people. However, HI risk related to the level of activities should not discourage leisure activities and help raise awareness and adaptation of the living environment to the risks by mapping foreseeable hazards.

\section{Limitations and strengths}

Common limitations observed in volunteer-based cohorts and e-cohorts are low response rates, volunteer bias, loss of follow-up and self-administered questionnaires, leading to selection biases and missing and selective answers. Young adults and people from low socioeconomic groups and low levels of educational attainment were under-represented. ${ }^{21}$ As with other e-cohorts, ${ }^{34}$ we made continuous efforts to address representativeness, underreporting of the outcome, data reliability and loss to follow-up. ${ }^{21}$

Back pain, sciatica, vertigo and dizziness are relatively prevalent conditions and sometimes show chronic patterns with frequent sick episodes. These two characteristics are generally associated with higher data reliability. ${ }^{35}$ However, we cannot rule out the existence of misclassification, especially when the diagnostic criteria is 'vague', or the disease is perceived as 'less severe', or the diagnosed disease is confounded with symptoms or signs of illness. ${ }^{36} 37$ We systematically requested the diagnosis dates to mitigate this problem. Among younger adults, we hypothesise a low level of misclassified cases because, being 
Table 3 Factors associated with the incidence of HI, relative to the time at risk at home, in adults of the MAVIE (Mutualistes pour la recherche contre les Accidents de la VIE courante) cohort by age group

\begin{tabular}{|c|c|c|c|c|c|c|c|}
\hline & \multicolumn{3}{|c|}{ Adjusted models } & \multicolumn{4}{|c|}{ Fully adjusted models } \\
\hline & $(\%)$ & $\mathrm{RR}(95 \% \mathrm{Cl})$ & $P_{c}$ & $(\%)$ & $\mathrm{RR}(95 \% \mathrm{Cl})$ & $P$ value & $\operatorname{AF}(\%)$ \\
\hline Age 15-49 & \multicolumn{3}{|c|}{$(\mathrm{N}=1887, \mathrm{HI}=208)$} & \multicolumn{4}{|c|}{$(\mathrm{N}=1804, \mathrm{HI}=205)$} \\
\hline \multicolumn{8}{|l|}{ Sciatica or back pain } \\
\hline Yes (vs no) & (14) & 2.40 (1.49 to 3.91$)$ & $<0.001$ & $(14)$ & $2.26(1.40$ to 3.65$)$ & 0.001 & 11.9 \\
\hline \multicolumn{8}{|l|}{ Vertigo or dizziness } \\
\hline Yes (vs no) & (2) & $4.95(1.76$ to 13.75$)$ & 0.002 & (1) & $4.59(1.48$ to 14.13$)$ & 0.007 & 3.2 \\
\hline \multicolumn{8}{|l|}{ Comorbidity } \\
\hline$\geq 2$ diseases (vs 1 disease or not disease) & (41) & 2.15 (1.45 to 3.22$)$ & $<0.001$ & - & - & - & \\
\hline Age $50+$ & \multicolumn{3}{|c|}{$(n=2915, H I=472)$} & \multicolumn{4}{|c|}{$(n=259, H I=468)$} \\
\hline \multicolumn{8}{|l|}{ Other musculoskeletal system diseases } \\
\hline Yes (vs no) & (21) & 1.57 (1.19 to 2.07$)$ & 0.005 & $(22)$ & 1.45 (1.05 to 1.98$)$ & 0.023 & 9.3 \\
\hline \multicolumn{8}{|l|}{ Sciatica or back pain } \\
\hline Yes (vs no) & (21) & $1.36(1.03$ to 1.80$)$ & 0.031 & $(21)$ & 1.09 (0.78 to 1.52$)$ & 0.602 & 2.2 \\
\hline \multicolumn{8}{|l|}{ Arthropathies } \\
\hline Yes (vs no) & (17) & $1.37(1.02$ to 1.84$)$ & 0.036 & (18) & $1.14(0.81$ to 1.59$)$ & 0.458 & 2.7 \\
\hline \multicolumn{8}{|l|}{ Comorbidity } \\
\hline$\geq 2$ diseases (vs 1 disease or no disease) & (53) & $1.35(1.05$ to 1.75$)$ & 0.036 & - & - & - & \\
\hline
\end{tabular}

Poisson mixed models including offset term time spent at home during the follow-up and random effect in the variable household. Adjustment variables: Age 15-49 (gender, history of injuries).

Age 50+ (gender, history of injuries, living alone, household income level, DIY/gardening, frequency of alcohol consumption).

Bold indicates $p$ values $<0.05$.

$A F$, attributable fraction; $\mathrm{HI}$, number of home injuries; $\mathrm{N}$, number of responders; $\mathrm{P}_{\mathrm{c}^{\prime}} \mathrm{p}$ values ANOVA type Il corrected using the Benjamini and Hochberg (1995) method.

generally in very good health, a modest deterioration in their health status may be perceived as relatively important. Among older participants, we think that the involvement of a reference person to communicate household information might increase the reliability of the data. However, this representation could decrease the willingness to report private information. The high follow-up rate of the MAVIE cohort suggests that participants are motivated to response.

Regarding other limitations, the study design does not allow us to disentangle the effects of health conditions and their treatments. Moreover, information about disease severity, individual risk-taking and risk awareness was not available. Finally, we measured health conditions at a single time point; health changes were not assessed over time.

\section{CONCLUSION}

Despite these limitations, the MAVIE cohort is the injury observatory with the most detailed sociodemographic, contextual and exposure information to study risk factors of HLIs in France. This information enabled us to control for potential confounders and account for exposure time, the latter being a rare opportunity.

Acknowledgements The authors express their thanks to all IETO team members for their help, especially Juan Naredo Turrado, Jeanne Duchesne, Li Lu and MarieOdile Coste.

Contributors All authors contributed to the study conception and design. Methodology: MYRC, MA and EL. Formal analysis: MYRC. Investigation: MYRC, MA, $L O$ and EL. Writing original draft: MYRC. Writing review and editing: MA, BC, MD, CS-K, LO and EL. Supervision: EL and MA. Project administration: EL, CS-K and MD. Funding acquisition: EL, CS-K and MD.

Funding This study was financed jointly by the Institut de recherche en santé publique (IReSP) (CONV 067-00187II), the Agence nationale de sécurité du medicament et des produits de santé (conv 2014S029), the Université de Bordeaux and the Région Nouvelle Aquitaine as part of the Cassiopée project (conv 2014-
1R30504-00003101). MYRC is the recipient of an INSERM/Région Nouvelle Aquitaine doctoral grant (2017-1R40301 Thèse 00013329) and is affiliated to the Graduate Digital Public Health Program supported within the framework of the PIA3 (Investment for the future) (17-EURE-0019). The MAVIE observatory has the support of the mutual insurance companies: Fondation MAIF, MAAF, MACIF and Decathlon (AD 13339, AD 15404).

Competing interests None declared.

Patient consent for publication Not required.

Ethics approval The French Data Protection Authority approved the protocol of this study. The study is declared to the Commission Nationale de I'Informatique et des Libertés (CNIL) under file number 912292. Identifying data were stored

\section{What is already known on the subject}

- There is evidence that a large number of health conditions increase home injury (HI) risk in older adults.

- Musculoskeletal system diseases increase the risk of falls at home in older adults through weakness, loss of posture and balance.

- There is a lack of evidence on how health conditions affect the risk of $\mathrm{HI}$ in younger adults.

\section{What this study adds?}

- Our results suggest a moderate to high effect of musculoskeletal system diseases and vertigo or dizziness symptoms over HI risk regardless of age.

- Back pain or sciatica is the group of conditions with the highest attributable fraction of $\mathrm{HI}$ risk among all adults and adults under 50 years old. 
on servers located in a different location from those hosting the main database. Electronic informed consent was collected from all adult participants. Participation of children was done under the responsibility and with the consent of a legal guardian.

Provenance and peer review Not commissioned; externally peer reviewed.

Data availability statement Data are available on reasonable request.

Supplemental material This content has been supplied by the author(s). It has not been vetted by BMJ Publishing Group Limited (BMJ) and may not have been peer-reviewed. Any opinions or recommendations discussed are solely those of the author(s) and are not endorsed by BMJ. BMJ disclaims all liability and responsibility arising from any reliance placed on the content. Where the content includes any translated material, BMJ does not warrant the accuracy and reliability of the translations (including but not limited to local regulations, clinical guidelines, terminology, drug names and drug dosages), and is not responsible for any error and/or omissions arising from translation and adaptation or otherwise.

ORCID ID

Emmanuel Lagarde http://orcid.org/0000-0001-8031-7400

\section{REFERENCES}

1 Keall MD, Ormandy D, Baker MG. Injuries associated with housing conditions in Europe: a burden of disease study based on 2004 injury data. Environ Health 2011;10:98.

2 Eurosafe. Injuries in the European Union. summary of injury statistics for the years 2012-2014. Available: https://www.eurosafe.eu.com/uploads/inline-files/EuropeSafe_ Master_Web_02112016\%20\%282\%29.pdf [Accessed 16 Apr 2021].

3 Keall MD, Baker M, Howden-Chapman P, et al. Association between the number of home injury hazards and home injury. Accid Anal Prev 2008;40:887-93.

4 Laurence BD, Michel L. The fall in older adults: physical and cognitive problems. Curr Aging Sci 2017;10:185-200.

5 Ambrose AF, Paul G, Hausdorff JM. Risk factors for falls among older adults: a review of the literature. Maturitas 2013;75:51-61.

6 Deandrea S, Lucenteforte E, Bravi F, et al. Risk factors for falls in community-dwelling older people: a systematic review and meta-analysis. Epidemiology 2010;21:658-68.

7 Marshall LM, Litwack-Harrison S, Makris UE, et al. A prospective study of back pain and risk of falls among older community-dwelling men. J Gerontol A Biol Sci Med Sci 2017;72:1264-9.

8 Marshall LM, Litwack-Harrison S, Cawthon PM, et al. A prospective study of back pain and risk of falls among older community-dwelling women. J Gerontol A Biol Sci Med Sci 2016;71:1177-83.

9 Dionyssiotis Y. Analyzing the problem of falls among older people. Int I Gen Med 2012;5:805-13.

10 Choi NG, Choi BY, DiNitto DM, et al. Fall-Related emergency department visits and hospitalizations among community-dwelling older adults: examination of health problems and injury characteristics. BMC Geriatr 2019;19:1-10.

11 Alyono JC. Vertigo and dizziness: understanding and managing fall risk. Otolaryngol Clin North Am 2018;51:725-40.

12 Cho B-Y, Seo D-C, Lin H-C, et al. BMI and central obesity with falls among communitydwelling older adults. Am J Prev Med 2018;54:e59-66.

13 Hatcher VH, Galet C, Lilienthal M, et al. Association of clinical frailty scores with Hospital readmission for falls after index admission for trauma-related injury. JAMA Netw Open 2019;2:e1912409.

14 Seppala LJ, Wermelink AMAT, de Vries M, et al. Fall-Risk-Increasing drugs: a systematic review and meta-analysis: II. psychotropics. J Am Med Dir Assoc 2018;19:371. e11-371.e17.
15 Yoshikawa A, Ramirez G, Smith ML, et al. Opioid use and the risk of falls, fall injuries and fractures among older adults: a systematic review and meta-analysis. J Gerontol $A$ Biol Sci Med Sci 2020;75:1989-95.

16 Zia A, Kamaruzzaman SB, Tan MP. Polypharmacy and falls in older people: balancing evidence-based medicine against falls risk. Postgrad Med 2015;127:330-7.

17 Talbot LA, Musiol RJ, Witham EK, et al. Falls in young, middle-aged and older community dwelling adults: perceived cause, environmental factors and injury. BMC Public Health 2005;5:1-9.

18 Palmer KT, Harris EC, Coggon D. Chronic health problems and risk of accidental injury in the workplace: a systematic literature review. Occup Environ Med 2008;65:757-64.

19 Stenbacka M, Jansson B, Leifman A, et al. Association between use of sedatives or hypnotics, alcohol consumption, or other risk factors and a single injurious fall or multiple injurious falls: a longitudinal general population study. Alcohol 2002;28:9-16

20 Schellenberg M, Inaba K, Chen J, et al. Falls in the Bathroom: A Mechanism of Injury for All Ages. J Surg Res 2019;234:283-6.

21 Rojas MY, Orriols L, Contrand B, et al. Cohort profile: MAVIE a web-based prospective cohort study of home, leisure, and sports injuries in France. PLoS One 2021;16:e248162

22 Huntley AL, Johnson R, Purdy S, et al. Measures of multimorbidity and morbidity burden for use in primary care and community settings: a systematic review and guide. Ann Fam Med 2012;10:134-41.

23 Brooks Mollie,E., Kristensen K, Benthem Koen,J.,van, et al. glmmTMB balances speed and flexibility among packages for Zero-inflated generalized linear mixed modeling. $R$ J 2017:9:378-400.

24 Venzon DJ, Moolgavkar SH. A method for computing Profile-Likelihood-Based confidence intervals. Journal of the Royal Statistical Society: Series C 1988;37:87-94.

25 Benjamini Y, Hochberg Y. Controlling the false discovery rate: a practical and powerful approach to multiple testing. Journal of the Royal Statistical Society: Series $B$ 1995;57:289-300

26 Flegal KM, Williamson DF, Graubard BI. Using adjusted relative risks to calculate attributable fractions. Am J Public Health 2006;96:398.

27 Moriarty $\mathrm{O}, \mathrm{McGuire} B \mathrm{~B}$, Finn DP. The effect of pain on cognitive function: a review of clinical and preclinical research. Prog Neurobiol 2011;93:385-404.

28 Bisdorff A. Migraine and dizziness. Curr Opin Neurol 2014;27:105-10.

29 Zarcone D, Corbetta S. Shared mechanisms of epilepsy, migraine and affective disorders. Neurol Sci 2017;38:73-6.

30 Shi $\mathrm{X}$, Wheeler KK, Shi J, et al. Increased risk of unintentional injuries in adults with disabilities: a systematic review and meta-analysis. Disabil Health J 2015;8:153-64.

31 Kopjar B, Wickizer TM. Population-Based study of unintentional injuries in the home. Am J Epidemiol 1996;144:456-62.

32 Jiang C, Xu Y. The association between mild cognitive impairment and doing housework. Aging Ment Health 2014;18:212-6.

33 Tsuchiya K, Mitsui S, Fukuyama R, et al. An acute bout of housework activities has beneficial effects on executive function. Neuropsychiatr Dis Treat 2018;14:61-72.

34 Nittas V, Alan Puhan M, Wyl von V. Toward a working definition of ecohort studies in health research: narrative literature review. JMIR Publications Inc 2021;7:e24588.

35 Smith B, Chu LK, Smith TC, et al. Challenges of self-reported medical conditions and electronic medical records among members of a large military cohort. BMC Med Res Methodol 2008;8:37.

36 van den Akker M, van Steenkiste B, Krutwagen E, et al. Disease or no disease? disagreement on diagnoses between self-reports and medical records of adult patients. Eur J Gen Pract 2015;21:45-51.

37 Lenderink AF, Zoer I, van der Molen HF, et al. Review on the validity of self-report to assess work-related diseases. Int Arch Occup Environ Health 2012;85:229-51. 